\title{
THE EFFECT OF CAFFEINE ON TEAR FORMATION
}

\author{
BY
}

\author{
*AMAECHI, O. U. AND SAVIA, J. \\ DEPARTMENT OF OPTOMETRY, ABIA STATE UNIVERSITY \\ UTURU, ABIA STATE, NIGERIA \\ Email:okamaechi@yahoo.com \\ *Corresponding author
}

\begin{abstract}
The effect of caffeine on tear formation of thirty young healthy subjects (mean age: $22.27 \pm 2.7 \mathrm{yrs}$ ), was studied using Schirmer test 1 . The Pre-test, post-test method of experimental design was used. The tear formation was evaluated before and after intake of $150 \mathrm{ml}$ cup of coffee (caffeine concentration of $1.65 \mathrm{~g} / \mathrm{l}$ derived by dissolving a teaspoon of pure coffee in $150 \mathrm{ml}$ of water). The post-test was at hourly intervals over a period of four hours. A reduction in tear formation from the mean baseline value $(22.5 \mathrm{~mm})$ was recorded after the hourly intervals thus $19.67 \mathrm{~mm}, 13.73 \mathrm{~mm}, 15.50 \mathrm{~mm}$ and $16.18 \mathrm{~mm}$ at $1 \mathrm{hr}, 2 \mathrm{hrs} 3 \mathrm{hrs}$ and 4 hrs respectively. This showed a percentage reduction of $12.58 \%, 38.98 \%, 31.11 \%$ and $28.09 \%$ respectively. The greatest reduction was therefore recorded $2 \mathrm{hrs}$ after intake of caffeine. This effect was significant $(\mathrm{P}>0.05)$ using the paired t-test. It may be necessary to advise patients with symptoms of dry eye to avoid caffeinated substances so as not to aggravate their condition.
\end{abstract}

KEYWORDS: Caffeine, Dry eye, Schirmer test 1, TBUT test, Tears formation.

\section{INTRODUCTION}

Caffeine is a methylxanthine, and be derived form such sources as kola nuts, coffee beans and cocoa. It is contained in most of the things we eat, and drink like chocolates, cola drink, coffee, tea, cocoa, drink and many other beverages,. As stated by Goodman and Gilman ${ }^{1}$, the different sources of caffeine very in their caffeine content thus: 1 cup of coffee (150ml): $67-175 \mathrm{mg}$ of caffeine; 1 cup of tea (150ml): $50 \mathrm{mg}$ caffeine, $1 \mathrm{mg}$ theophylline; 1 cup of cocoa $(150 \mathrm{ml}): 5 \mathrm{mg}$ caffeine, $250 \mathrm{mg}$ theobromine; $12 \mathrm{oz} / 36 \mathrm{c} 1$ bottle of cola drink: $40-$ $50 \mathrm{mg}$ caffeine; 1 bar of chocolate: $25 \mathrm{mg}$ caffeine per $30 \mathrm{~g}$.

The effects of caffeine in the body are dose related. The effect on the body systems could be subtle at low doses, overt at high doses, and the consumers are at risk of becoming victims of caffeine addiction ${ }^{2}$. It has such effects as stimulation of mental activity, increase in blood pressure and heart rate, smooth muscle relaxation (thus bronchodilator), diuresis, sleep disruption, improvement in physical performance and other. Caffeine is of great therapeutic importance being used in treatment of neonatal apnea and dyspnea, and it serves as an adjuvant in several pharmaceutical preparations ${ }^{3}$. Caffeine affects the nervous system, and therefore the production of aqueous tears by the lachrymal gland, which depends on the nervous system.
The tear film is composed of 3 layers, with the aqueous layer secreted by the lachrymal gland, forming the bulk of its volume. Both cholinergic and adrenergic fibers innervate the lacrimal gland; however, unstipulated tearing is controlled by the parasympathetic nervous system ${ }^{4}$. The lacrimal function is also influenced by other factors like age, menopause, certain drugs, and pathologic condition.

Caffeine has anticholinergic effects by its antagonism of adenosine receptors, and thus potential effect on the lacrimal gland formation. The reduction of glandular secretion induced by caffeine is one of its many anticholinergic effect ${ }^{5}$. Among agents that frequently reduce tear secretion are the anticholinergics, antihistamines and antianxiety drugs ${ }^{6}$.

A habitual caffeine user may therefore experience certain symptoms, which are generally associated with tear deficiency. The aim of this study is to ascertain if caffeine has a significant effect on tear formation, which would lead to an improvement in the quality of management given to such individuals.

\section{MATERIALS AND METHODS}

The pre-test, post-test experimental design was used in this study. Thirty healthy subjects aged 1830years were randomly selected irrespective of gender, tribe or occupation from Owerri, Imo state, 
Nigeria. These subjects were selected after a thorough case history, relevant preliminary tests, external examination, ophthalmoscopy and tear breakup time (TBUT) test to ensure good ocular and systemic health.

Habitual caffeine users, elderly patients, pregnant women, cigarette smokers and dry eye patients were not used in the study.

A proper drug and social history was necessary to eliminate the presence of drugs/substances that could modify the effect of caffeine and thus affect the study. Individuals on such drugs as anticholinergics, antihistamines, sedatives, contraceptive, etc were disqualified, because of the influence of such drugs on the lacrimal gland function ${ }^{6}$ Elderly people were not used, because their age predisposes them to dry eye and associated symptoms as well as other systemic diseases.

Habitual caffeine users were disqualified from the study, because of the tendency for them to develop tolerance to its effect ${ }^{7}$. The TBUT test was used to identify and eliminate mucin deficient eyes; these are individuals with TBUT values of less than 10 seconds $^{8}$.

Schirmer test 1 , as described by Newell ${ }^{8}$, was performed on the selected subjects after which, they were given $150 \mathrm{ml}$ cup of coffee (equivalents to $250 \mathrm{mg}$ of caffeine). The subjects therefore acted as their own control. The coffee drink was got by adding one level teaspoon of Maxwell House ${ }^{\circledR}$ instant coffee granules to $150 \mathrm{ml}$ of warm $\operatorname{swan}^{\circledR}$ water (a caffeine concentration of $1.65 \mathrm{~g} / \mathrm{l}$ ). Schirmer test was then repeated at hourly intervals over a period of 4 hours, since the onset of effect of caffeine occurs within an hour and lasts for 3-4 hours ${ }^{2}$.

The paired t-test, at 0.05 level of significance, was used to test for significant induced effect due to intake of caffeine.

\section{RESULTS}

The tear formation mean baseline value $(22.5 \mathrm{~mm})$ reduced to $19.67 \mathrm{~mm}, 13.73 \mathrm{~mm}$, $15.50 \mathrm{~mm}$ and $16.18 \mathrm{~mm}$ at $1 \mathrm{hr}, 2 \mathrm{hrs}$, 3hrs $4 \mathrm{hrs}$ interval respectively; a mean percentage reduction of $12.58 \%, 38.98 \%, 31.11 \%$ and $28.09 \%$ respectively (table 1). The greatest induced change was at $2 \mathrm{hrs}$ after caffeine intake (table 2). The statistical analysis showed the t-critical values to be greater than the $\mathrm{t}$-statistic value $\left(\mathrm{t}_{\text {tab }} 2.045<\mathrm{t}_{\text {cal }}\right.$ $2.390,6.556,7.374,6.959$ for the respective time intervals).

\section{DISCUSSION}

The results showed a decrease in tear formation after the intake of $150 \mathrm{ml}$ of coffee (table 1 ). The values got at the hourly intervals over a period of 4 hours were lower than the baseline value, but the greatest decrease was in the second hour (table 2). This decrease in tear formation was significant using the t-test at the 0.05 level of significance.

The manifest effect of caffeine on tear formation, 1 hour after intake, could be explained by the fact that caffeine attains maximum plasma concentration within an hour ${ }^{1}$ and that the onset of its effect occurs within an hours. The values got at the hourly intervals after over a period of 4 hours remained lower than the baseline values because caffeine has physiological half-life of 3 hours ${ }^{9}$ to 6 hours ${ }^{10}$ and duration of effect within the range of 34 hours $^{2}$.

The reduction effect of caffeine on tear formation is because of its anticholinergic effects hence a reduction in lacrimal gland formation ${ }^{4}$ It is suggested that individuals experiencing symptoms of dry eye avoid caffeinated substances so as not to exacerbate the problem.

TABLE 1: MEAN TEAR FORMATION VALUES PRE AND POST CAFFEINE INTAKE

\begin{tabular}{|l|l|l|l|l|l|l|}
\hline Age group & $\mathbf{N}$ & $\begin{array}{l}\text { Mean } \\
\text { Baseline }\end{array}$ & \multicolumn{4}{|c|}{ Mean post administration } \\
\cline { 4 - 7 } & & & lhr & 2hrs & 3hrs & 4hrs \\
\hline $18-22$ & 16 & 22.30 & 19.74 & 15.00 & 16.37 & 17.18 \\
\hline $22-26$ & 11 & 20.90 & 18.27 & 13.18 & 14.54 & 15.36 \\
\hline $26-30$ & 3 & 24.30 & 21.00 & 13.00 & 15.61 & 16.00 \\
\hline Total & 30 & 67.50 & 59.01 & 41.18 & 46.51 & 48.54 \\
\hline Mean & - & 22.50 & 19.67 & 13.73 & 15.50 & 16.18 \\
\hline Mean \% reduction & - & - & $12.58 \%$ & $38.98 \%$ & $31.11 \%$ & $28.09 \%$ \\
\hline
\end{tabular}


\#AMAECEII, 0. U. AND SAVIA, J.

TABLE 2: MEAN INDUCED DECREASE IN TEAR FORMATION

\begin{tabular}{|l|l|l|l|l|}
\hline Age group & $\triangle \mathbf{1} \mathbf{h r}$ & \multicolumn{1}{|}{$\mathbf{h r s}$} & \multicolumn{1}{|c|}{$\mathbf{3} \mathbf{h r s}$} & $\triangle \mathbf{4 h r s}$ \\
\hline $18-22$ & 2.56 & 7.30 & 5.93 & 5.12 \\
\hline $22-26$ & 2.63 & 7.72 & 6.36 & 5.54 \\
\hline $26-30$ & 3.30 & 11.30 & 8.70 & 8.30 \\
\hline Total & 8.49 & 26.32 & 20.99 & 18.96 \\
\hline Mean & 2.83 & 8.77 & 7.00 & 6.32 \\
\hline
\end{tabular}

\section{R E F E R E N C E S}

1. Goodman, L. and Gilman, A. (1996): The pharmacological basis of Therapeutics. $9^{\text {th }}$ Edn. The McGraw-Hill Companies, 918pp.

2. Sanford, B. and Gary Null, M. S. (1981): Caffeine: Psychological Effects, Use and Abuse. J. Orthomolecular Psychiatry, 10 (3): 202-11.

3. Bertram, K. (1995): Basic and Clinical Pharmacology. $6^{\text {th }}$ Edn. Appleton and Lange, 1046pp.

4. Jannus, S. D. and Bartlett, J. D. (2001): Adverse Ocular effects of systemic drug therapy. In Bartlett J.D. and Jaanus S.D. Clinical Ocular Pharmacology. $4^{\text {th }}$ Edn. Butterworth-Heinemann, pp917-39.

5. Madder, T. H. (1991): Keratocnjunctivitis sicca caused by diphenoxylate hydrochloride with atropine sulfate. Am. J. Ophthalmol, 111:357-9.

6. Grand all, D. C. and Leopold, H. (1979): The influence of systemic Drugs on Tear constituents. J. Ophthalmol, 86:115-25.

7. Stephenson, P. E. (1977): Physiologic and psychotropic Effects of caffeine on man. J. Am. Deitic.Assoc, 71 (2):240-2.

8. Newell, F. W. (1982): Ophthalmology: Principles and concepts. $5^{\text {th }}$ Edn. The C. V. Mosby Co, St Louis, Toronto, London, 559pp.

9. Parsons, W. D. and Neims, A. H. (1978): Effect of smoking on caffeine clearance. J. Clin. Pharm. Ther, 24(1): 40-5.

10. Aranda, J. V., Null, G. and Bolton, S. (1979): Pharmacokinetic profile on caffeine in premature newborn Infant with Apnea. J. Pediat, 94(4): 663-6. 